\title{
Network among Institutions: The Case of TORINO Model
}

\author{
Maura Campra ${ }^{1}$, Silvana Secinaro ${ }^{2} \&$ Valerio Brescia ${ }^{2}$ \\ ${ }^{1}$ Department of Economics and Business Studies, University of Piemonte Orientale "Amedeo Avogadro", Novara \\ (NO), Italy \\ ${ }^{2}$ Department of Management, University of Turin, Torino (TO), Italy \\ Correspondence: Department of Management, University of Turin, C.so Unione Sovietica, 218 bis, 10134, \\ Torino (TO), Italy. E-mail: valerio.brescia@unito.it
}

Received: January 19, 2019

doi:10.5539/ijbm.v14n4p116
Accepted: February 18, 2019

Online Published: March 8, 2019

URL: https://doi.org/10.5539/ijbm.v14n4p116

\begin{abstract}
The network is a model that may be able to respond to public needs by overcoming some limitations of other approaches. In literature, a generalizable model is often absent and not applicable to more than one productive sector. The case study uses the "Torino Model" to highlight the most frequent features and measurable elements of the network through a bottom-up coding approach by ATLAS software. The case is analyzed through interviews, documents analysis and observation of the functioning of the network. Sustainability, management and the main network outcomes are the elements that the study examines the case study. The analysis responds to the gap identified in the literature concerning the application to a system composed of institutions. The essential elements linked to know-how, the exchange of training and information and therefore the growth of intangible value constitute the essential basis for the establishment of a successful network, and this is also highlighted by the case study. The case study highlights how the network between institutions reduces costs by eliminating the duplication of services offered and increasing effectiveness and efficiency through increasing other factors such as the professional ability to respond to needs by immediately putting institutions and professionals in communication. The model confirms the ability to overcome the gap related to the network between institutions and between public and private, increasing the well-being of the local system.
\end{abstract}

Keywords: network, sustainability, governance network, accounting association

\section{Introduction}

In the last 30 years, the public sector has been increasingly oriented towards meeting the needs of stakeholders. Freeman defined a stakeholder as "any group or individual who can influence or is influenced by the achievement of the organization's goals" (Borgonovi, 2005; Harrison, \& Freeman, 1999). Key stakeholders must be satisfied, at least minimally, otherwise public policies, organizations, communities or even countries and civilizations will fail (Bryson, 2004; Friedman \& Miles, 2002). To survive in the longer term in an unstable and uncertain environment, or to achieve organizational sustainability, contemporary organizations must satisfy a variety of stakeholders, all of whom are capable of inflicting unacceptable damage on the organization's profitability if their interests are not met. Depending on the type of companies, these stakeholders may include customers, collaborators, suppliers, lenders, owners or members of various other pressure groups (Freeman, 1984; Schilling, 2000; Wreder, Johansson, \& Garvare, 2009). The notion of 'stakeholder management' for organizational sustainability has been described as an organization behaving in such a way as to satisfy the needs and expectations of its stakeholders (Garvare \& Johansson, 2010). A company should meet, or preferably exceed, the needs and expectations of its customers, subject to meeting the demands of other interested parties. The appropriateness that the term wants is not obvious. Bergman and Klefsjö, (2010), for example, prefer the term needs. Reforms involving the managerialization of public administrations (Farnham, Hondeghem, Horton, \& Barlow, 2016) work on the assumption that improving the mechanisms of governance and responsibility also improves performance in the public sector (C Pollitt \& Bouckaert, 2004; Christopher Pollitt \& Bouckaert, 2011). An analysis of the literature shows that public sector governance concerns the responsibilities related to the specific objectives of this sector, which are not only limited to the provision of services (for example, the cost and quality of a service), but also include the impact of policies on the community and on society for example, political or taxation-related outcomes (Jacobs \& Goddard, 2007) and setting rules and guarantee rights (Bovaird, 2007; Stewart \& Walsh, 1992). Since the beginning of the 70s we find the use of networks as an embryonic 
model of bottom-up implementation able to increase intergovernmental relations to answer the need (Hanf \& Scharpf, 1978; Hjern \& Porter, 1981). In other studies, the network is identified as the interaction between a multitude of actors (Cohen, March, \& Olsen, 1972; Lecy, Mergel, \& Schmitz, 2014; Lindblom, 1965; Sorensen $\&$ Torfing, 2005) or as a collaboration between sectors (Bryson, Crosby, \& Stone, 2006). The study, starting from the reference literature on the subject of networks between institutions, analyzes the possible factors of impact on the system through a case study. The reference literature highlights a GAP related to the effectiveness of the theoretical models related to sustainability and the fallout of the network. There is no literature related to the effective relapse of the network between institutions, considering the entire local level of institutions and not limited to a specific sector or event. The analysis highlights the characteristics found and the actual impact of the case study taking into account the models defined in the literature. The article intends to analyse whether the case study possesses the key elements sufficient to affirm that the new model of hybrid network (public and private) of service based on a professional order has positive outcomes on the territory useful to support the community increasing sustainability. The work is part of the international debate related to the development of the network, the key elements, the drivers and the model structure with a view to sustainable community outcomes. The paper is structured in five chapters. The reference literature review is then defined. The methodology analyzed immediately shows the characteristics identified in the "Torino Model" case study. The discussion analyzes the functioning of the network, characteristics and approach both in terms of historical development and in terms of confirmation or overcoming of the existing theory. The last chapter highlights the effective relapse of the model on the local system. The implications in terms of effectiveness and efficiency provided by the network and future development prospects.

\section{Literature Review}

\subsection{Approach to the Network and Territory}

The approach to the network, starting from these studies, focuses the attention on the interdependence process between actors, involving all the stakeholders useful to define the skills, knowledge, resources, and people necessary to answer the need (Agranoff \& McGuire, 2001; Dacin, Oliver, \& Roy, 2007). Attention is paid to the strategies implemented between the organizations to influence the different decisional processes of the territory with an exchange of information among the components (Booher \& Innes, 2002). All actors need to cooperate to respond to their needs, each subject stand as an antenna able to collect specific expressed needs. The network is, therefore, a useful tool and reality to achieve the result goals of the network in order to rationalize resources (O'Toole, 1988) and respond to needs. The number of networks composed of institutions has increased in recent years to find solutions to the problem related to infrastructure, fiscal deficit and inability to finance services of public interest (Campra, Oricchio, Braja, \& Esposito, 2014; Poocharoen \& Ting, 2015; Review \& 2003; Stadtler, Journal, \& 2012). The growth in demand for public services and goods includes roads, schools, hospitals, safety-related services, waste disposal and management, and emergency response (Beach, Keast, \& Pickernell, 2012; Forrer, Kee, Newcomer, \& Boyer, 2010). The inability to answer the needs of public enterprises often finds the necessity to privatize the provision or implementation of the service, sharing with these enterprises part of ownership and resources, funding and result targets (Hodge \& Greve, 2005; Mischen, 2015). This is possible only by overcoming the bargaining among subjects and switching to a mutable interaction of transparency and respect of all the interested parties. The ability to respond to the need and the responsibility are multiple in this approach, the public must respond primarily to the needs of the citizen and is responsible to him/her considering the allocation of resources, while private companies are responsible to the public for the objectives identified and shared with the production process, a mix of consensus and collaboration among companies is mandatory (Dowdle, Designs, \& 2006, n.d.; Wettenhall, 2007). The new approach among institutions must take into account the risk linked to the achievement of objectives, costs, and benefits, social and political impact, the experience to be put in place, the type of collaboration and the measurement of performance (Forrer et al., 2010). The presence of different institutions and enterprises with different interests requires the loss of a system based on a logic of government usually exercised by the public on the other actors or by the parent company on the subsidiaries, instead the logic passes to a governance system where different and autonomous subjects they try to achieve common goals (Considine \& Lewis, 2003). The network founded by institutions is based at the same time on two models of governance, the corporate governance that governs internal resources through management, capital and labour, and the system governance that integrates the market by allocating resources and responding better to the need through self-governance between subjects that autonomously define the allocation of resources according to need (Aguilera \& Jackson, 2003; Rhodes, 1996; Stoker, 1998). The network is therefore intended as a stable model of coordinated actions and exchanges of resources that involve actors and politicians and that cross different social scales, develop public, private, or non-profit in different sectors with different geographical 
levels. These elements interact through a variety of competitive levels, cooperative control, and negotiations related to one or more aspects of the policy flow (Koliba, Meek, \& Zia, 2010). In literature, Network Governance takes into account the interdependence of public, private and semi-private actors, acting as an advanced approach able to respond better to the needs of the territory, surpassing the New Public Management model (Benington \& Hartley, 2001). Currently, in order to better respond to needs, there are more and more mixed models of public-private organizations such as public-private partnerships where the contractual agreement provides for the division of public-private risk into the realization of large public works, "mixed organizations" with parts of the service provided by the private sector under the direction and control of the public that collects and codifies the needs, "hybrid organizations" complex organizations in which the public participates in private companies that sometimes controls and through different instruments guides the provision of services (Haigh \& Hoffman, 2012; Skelcher, 2005; Stoker, 1998; Warner \& Hefetz, 2008). The advancement and the new approach of Network management are based more on the inter-organizational mediation and coordination of common policies, overcoming the bureaucracy and rigidity of the previous model. This is highlight by numerous publications on network management in Europe (Driessen \& Glasbergen, 1995; Kickert, Klijn, \& Koppenjan, 1997; Rhodes \& Marsh, 1992; Wilks, Government-industry, \& 1987) and in the United States (Milward, unitary, \& 1985, n.d.; O'Toole, 1997; Provan \& Milward, 1995). There are several elements to be considered for the operation of the network. The first one is the social capital dedicated to achieving the objectives in order to mutate a common response needs (Fountain, 1998). In this case, by social capital, we mean the trust, the rules and the activities of the network linked to the objectives of the various subjects involved. The second element is the flexibility within the network, that is the ease of mobility of resources inside with a quick access to skills and technologies in order to face the needs and the market (Cristofoli, Macciò, \& Pedrazzi, 2015; Owen-Smith \& Powell, 2004), because the network is superior to the single enterprise in achieving efficiency. Also, in the network all the components are responsible for the management, there is no authority to monitor (Agranoff \& McGuire, 2001; E. H. Klijn \& Koppenjan, 2000). Among the external factors, we identify the ability to relate the different professional skills, the relational skills between staff in the reference context and the relationship dimension between different communities (Bruning, review, \& 1999). The dimension of the network is closely linked to the need and to the territory in which the network develops, the greater the demand for resources to put in place and the needs to be met, the greater the dimension that the network will assume; an example is the size of the networks trying to respond to social assistance needs (Graddy \& Chen, 2006). In particular, the purpose and size of the network depend on organizational factors (size, a dependence of resources, possessed experience), need for planning (required services, diversity and difference of customers) and development factors (availability of possible partners). Most studies address the issue of network and governance at the theoretical level without finding practical applications (Agranoff \& McGuire, 2001; Bruning et al., 1999; Graddy \& Chen, 2006; KLIJN, Koppenjan, administration, \& 1995; McGuire, 2006), in others the creation of a network is linked to exceptional events such as Hurricane Katrina (Koliba et al., 2010) or individual sectors, for example the development of networks in the different school districts (Hvidman, Administration, \& 2013; Meier \& O'Toole, 2003) or urban development and infrastructure (E.-H. Klijn \& Teisman, 2003), or the network organization of Community Mental Health Systems (Provan \& Milward, 1995) of the same state. In Torino (Italy) a network has been developed called "TORINO MODEL" that links institutions in the territory and aims to pursue objectives of common and collective relevance through teamwork and the synergy between local institutions, in the interest of the community and the civil society. It is a consolidated scheme, in reports and relationships, and open and dynamic in the composition and definition of projects. Our study intends to present the institutional Network, highlighting the typical elements through the case study, starting from the analysis of any case studies existing at European level and coming to identify the relapse on the territory. The professional order of accountants played a promoter role and allowed the development of the analyzed network model.

\subsection{Approaches to Network Management}

Two different strategies for network management are possible: the process management and network constitution (De Bruijn \& Ringeling, 1997; Klijn et al., 1995). Process management means the increase and interaction between actors and is aimed at solving the organizational problems between the different enterprises, in which each has its strategy that is not necessarily coherent with that of the others. In this case, some formal or informal rules must be set up to divide the resources and define common strategies by selecting the individual actors and the necessary resources to participate. The common perception is useful in this case to find solutions, as every enterprise can identify the problem and find solutions from a different point of view and with a different approach. In the network, therefore, packages of acceptable objectives converge to work together by the coalitions of actors. This can sometimes lead to the establishment of new organizations, as the individual organizations that make up the network are not sure of the achievement and the ability to respond to the need. An 
approach of this type requires constant supervision aimed at identifying the interaction between processes and the management of possible conflicts (Susskind, consensual, \& 1987). On the other hand, the network constitution is focused on the realization of the change in the network. The characteristics of the different actors influence strategies and cooperation with possible opportunities among the various subjects involved. Attention is focused on changing the position of the actors or introducing new actors into the model in order to generate a new perception and change of power among the subjects. The change of both formal and informal rules can influence the interaction by creating a change between the mechanisms of conflict. Redefining something is at the root of change and perception of problems.

\subsection{Governance Network and Accountability Framework}

The elements to be considered in the governance of a network always take into account the objectives of the alliance, the contractual reasons of the alliance and the formalization and organization of the partnership between the components defining together with the structure of the organization (Gulati, 1998). Control and government are only possible when the shares of power between the members are clear, this is only possible when there is a shared equity among the entities as in the joint ventures, otherwise it is difficult to replicate the control through structured elements of coordination between characteristics observable according to a spectrum of considerable hierarchies (Harrigan, 1987; Hennart, 1988; Osborn \& Baughn, 1990; Teece, 1992). Many studies focus on controlling transaction costs and the role and importance of information in the network with a decrease in contracting hazards and information uncertainty (Oxley, 1997; Pisano, 1989; Pisano, Russo, \& Teece, 1988). Scholars based on these assumptions suggest that hierarchical controls anticipate network formation. Romzek and Dubnik's model of responsibility (Romzek, review, \& 1987, n.d.) is questionable but provides the essential elements to be taken into consideration. Starting from the study of responsibilities related to the explosion of the space shuttle Challenger, the two authors illustrate four different structures of responsibility at work within NASA and among government actors in general: political, legal, bureaucratic and professional. In the $2 \times 2$ liability model, Romzek and Dubnick, jointly considering four frames of responsibility, dividing between the external and internal and high and low degree of control, suggest that that degree of control can be understood regarding bond strength. Presumably, stronger ties evoke higher levels of control. Within the governance networks, the degree of centrality and the relative strengths of the "controlling" entities are often highly contextual and contingent to the position of the organizational actors within the governance network. Without a governance network framework, the decisional levers are interpreted in vertical and horizontal terms as the relationship between who and by whom the responsibility is given (Bardach \& Lesser, 1996). Each responsibility is closely connected to a frame and relates based on the strength of the link between the actors in the absence of a governance network. The network must, therefore, take into account the different aspects based on the stakeholders and the types of responsibility that can be identified. Besides, the positioning in the network defines the role between actors, those who will be in the same position will be those who will have the relationships between them (Gulati, 1998). It is evident how the links expressed and possible are complex and require exemplifications to understand the possible consequences both internal and external to the enterprise. According to other scholars, the purely economic and financial approach to the role of the network and the related international discussion is useless because it is often based more on personal relationships (Laumann, Galaskiewicz, \& Marsden, 1978) or linked to repetitive social structures among the partners who therefore decide to define an alliance following of these relationships (Dyer \& Singh, 1998; Gulati, 1995; Nickerson \& Silverman, 1997; Ring \& de Ven, 1989).

\subsection{Criticism to the Approach}

Several criticisms of the network approach have been raised. The first one concerns the difficulty of understanding and knowing the results and the coherence of the actions carried out by the network (Borzel, 1998). Furthermore, it is difficult to investigate the outcome of process policy (Cristofoli, Meneguzzo, \& Riccucci, 2017; Dowding, 1995; Salancik, 1995). Focusing on network management the role of cooperation has more emphasis, often ignoring the conflict and the weight of differences (Brans, administration, \& 1997, n.d.). Network management often rejects the role of ex-ante rules and evaluation criteria. This approach is often considered insufficient to achieve governance goals (Propper, 1996). Moreover, in networks where public enterprises are present, the network rejects both the rules and the pursuit of the public interest. In these cases, the common good (Achrol, 1996) of networks is primary politics (De Bruijn \& Ringeling, 1997). The government and decision-making capacity are often not enough, given the high number and difference of interests of all the enterprises and institutions that make up the network, so there is often a risk that despite the resources made available, the objectives set by answering are not achieved as needed. This greatly affects the efficiency and effectiveness of the network. The difficulty of communicating between public and private, usually used to 
bargaining instruments, often affects internal cooperation (Elio Borgonovi, Marsilio, \& Musi, 2006). If public enterprises protect the common interest within the network, they can conflict with the different goals of profit companies. The rules and the bureaucratization of public enterprises clash with the need to respond to the needs of the flexibility of the network, and this can negatively affect the ability to answer the need.

\section{Method}

The study is based on an objective qualitative approach with a theoretical description and one applied through testing. The passage from the theoretical description, to development (Mintzberg, 2005) and finally the test (Szulanski \& Jensen, 2006) is realized through the "Torino Model" case study (Ring \& de Ven, 1989), focusing on some more relevant aspects related to the network. The case was analyzed through an interview, a document analysis and observation of the functioning of the network. The validity is guaranteed thanks to the trinagulation of the collected resources, in particular the interviews have allowed to codify the key elements, these have been verified through the analysis of the formalized contracts and subsequently through the observation of the real existence of the declared and formalized data. The observations are conducted before the formalization and subsequently in the three years of formalization of the model. The data are objective, and the contracts are present on the institutional website allowing the validity and reliability of the analyzed data (Silverman, 2005). In addition, previous research, discussion and relationship on the case study network were discussed. The reliability is characterized by the use of different methods (interview, observation and coding of formalized contracts) to define the outputs of the study (Denzin \& Lincoln, 1994). The context of the case study is analyzed (Cook \& Campbell, 1979). All interviews and observations were carried out by the authors and they involved administrative managers, members of the Association of Chartered Accountants Board and the founder of the network. The case study highlights the characteristics of the network between institutions, defining a new model of Government. The analysis of the main characteristics have been carried out through coding of main elements starting from the content of formal agreements. The analysis based on the formalized contracts was conducted with a bottom up coding approach by ATLAS software, elaborating density and (Bell, Bryman, \& Harley, 2018). An open coding technique was used in accordance with grounded theory (Corbin \& Strauss, 1990), whereby the main trends that emerge in the data are classified and classified with alphanumerical codes applied to the word such as phrases or paragraphs contained in the formal agreements. It is possible to identify values of strength and weakness with particular attention to the social impact. The coding analysis started from the identification of the elements and characteristics present in the formalized contacts. For each contract the presence and the relationship between the characteristics has been identified, in the appendix it is possible to check the existing lawyers. Density and grounded of the relationships between observable elements present in contracts formalized according to the relations of coexistence between characteristics is present in the table 1 .

Table 1. Grounded and density of elements in the formalised agreement of network "Torino Model"

\begin{tabular}{lrr}
\hline Code & Grounded & Density \\
\hline exchange training and information & 10 & 5 \\
Increase legality protection and reduction of tax damages and non-revenue for the territory & 5 & 2 \\
Increase quality public services & 8 & 5 \\
Job increase & 9 & 4 \\
Know how & 13 & 7 \\
Marketing and value intangible institutions & 2 & 3 \\
promotion of the network model & 4 & 5 \\
Research and development on the territory & 4 & 4 \\
Sustainability development & 6 & 5 \\
\hline
\end{tabular}

Source: own elaboration.

In order to better understand the link that unites the different characteristics observed, it is possible to construct a co-occurrence table (table 2). In this way it is immediately given evidence of the degree of relationship between the variables and the absence of the relationship between some of them in the agreements observed. Obviously, the relationships between the same variables as absent bonds should not be considered. The observation of the model allows to give evidence of the characteristics and the observable links between elements of the network and to verify how much the literature highlights and emphasizes. The nine characteristics analyzed in the network model identify a series of relationships mainly linked to their coherence within the formalized 
agreements. In particular, the know how is the most represented and is associated with job increase, the exchange of information and skills, the research and development of the territory, the promotion of the network model and its promotion within the network and outside, increasing the quality of services and sustainability in the area. The know how the main promoter of the model is therefore and at the embryonic level one of the main causes of the first embryonic model to strengthen the professional figure on which the whole model is based. In turn, the exchange of information and training facilitates the functioning of the model and provides the skills important for its continuous operation over time. This characteristic is linked in particular to know-how, to the growth of work, the growth of the intangible value of the network and institutions, to the promotion of the network model, to the increase of legality with the reduction of cases of tax damage. All other features are linked to each other and support and support the effectiveness and efficiency of the model.

Table 2. Co-occurrence table of elements of case study "Torino Model”

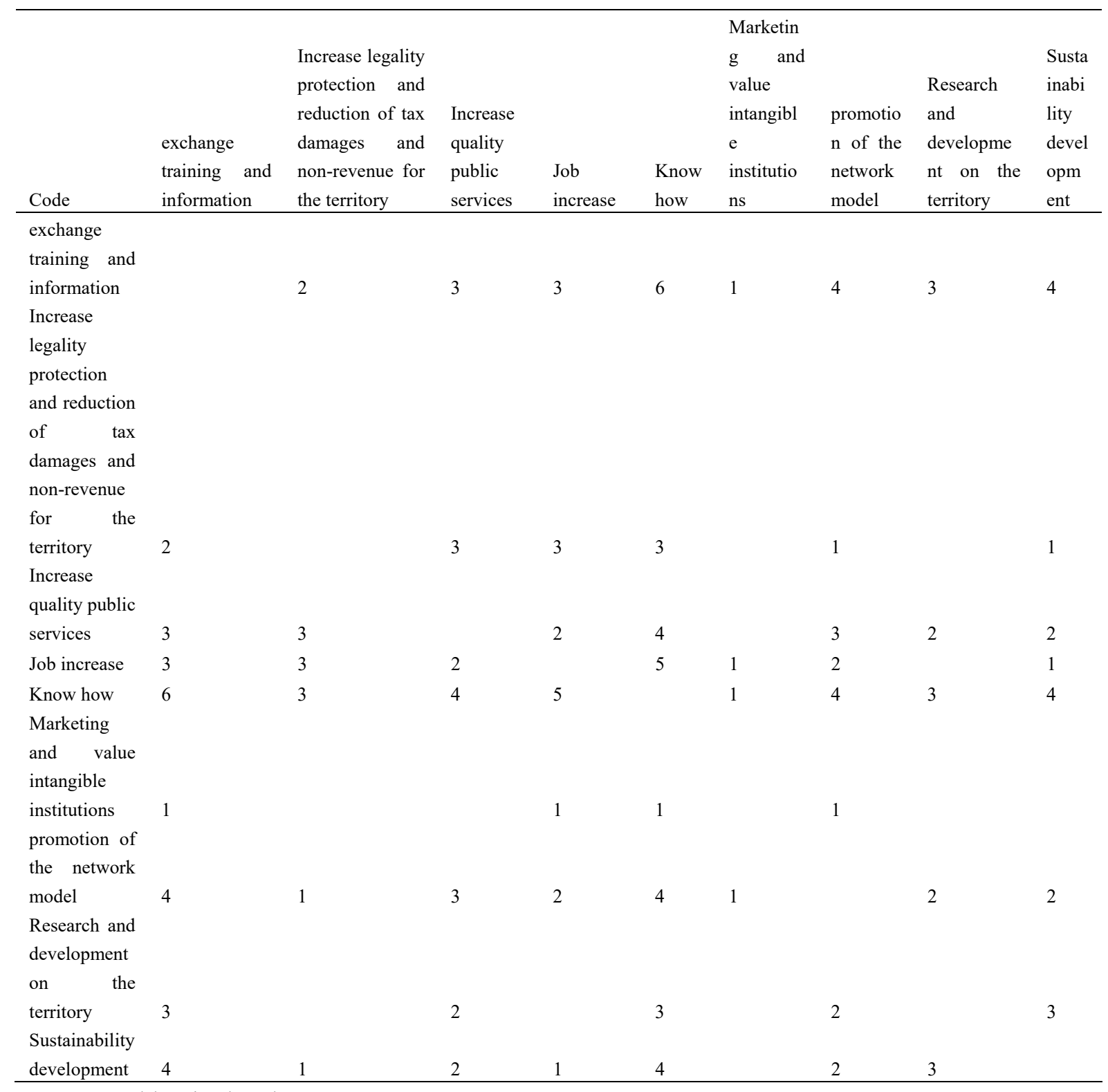

Source: own elaboration through ATLAS.

The presence of other case studies of service networks based on Professional Orders or professional associations with impact and general impact on the territory has been analysed without identifying similar cases. In this phase of the study it is therefore not possible to compare the characteristics and key elements identified with other case 
studies. Future analyses with the possibility of comparison should however follow the indications provided by using case studies in the study of contemporary business networks (Halinen \& Törnroos, 2005)

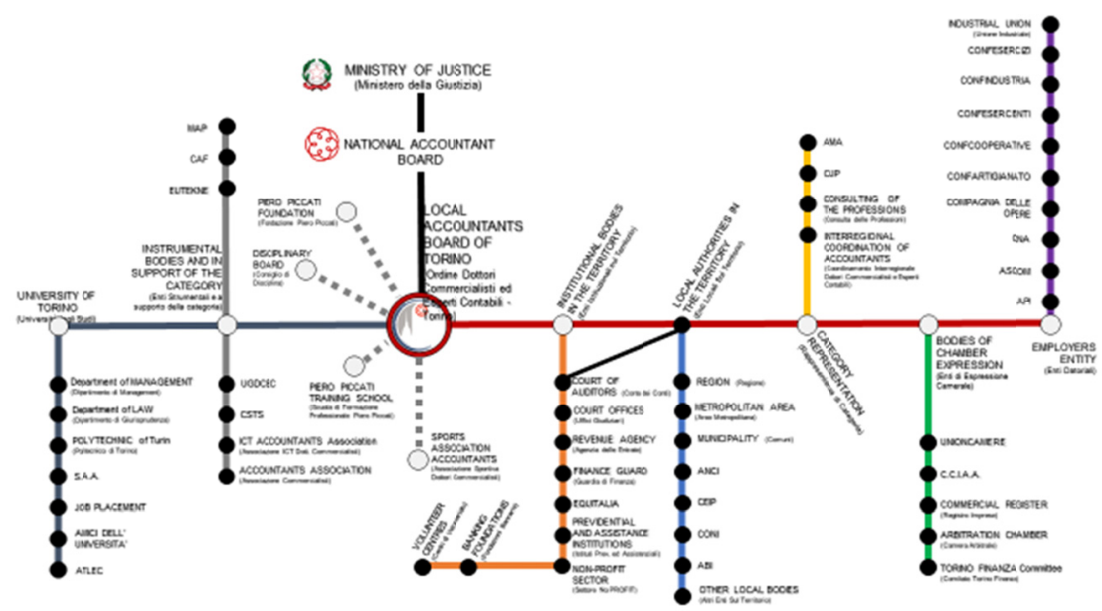

Figure 1. "Torino Model", example of network between institutions

Source: Local Accountants Board of Torino.

\subsection{Sample}

The "Torino Model" is a network driven by the objective of responding, based on different themes, the needs expressed by the territory. The Governance of the "Torino Model" is carried out by the Local Accountants Board of Torino by input from the members, institutions, and enterprises with which the Order has entered into several agreements. In Italy, the accountant is a qualified professional competent in economic-business matters, such assistance and start-up of commercial activity and merger acquisition, finance, taxation, accounting, and management. The formal title that belongs to this professional figure is an accountant (Dottore Commercialista). It must provide them with economic and fiscal assistance and must be able to carry out the appraisals, consultancies and technical assessments on anything that may concern the accounting activity of public and private enterprises, as well as traders, of artisans and other professionals. In order to become an accountant, it is necessary to have a master's degree in accounting, carry out a traineeship with another licensed accountant for a year and a half and take a state exam. To carry out the activity of an accountant, it is necessary first of all to register with the register as accountants in the association (a public body). The Local Accountants Board of Torino has a network of 3.794 members (of which 284 practitioners) spread throughout the territory. The "Torino Model" began in 1983 thanks to the impulse given by Secretary Aldo Milanese. Milanese from 2000 to 2016 became President and developed the model. The "Torino Model" developed when there were not yet national definitions of networks and analysis of practical cases. Before the creation of the "Torino Model," there was no link between the institutional subjects involved, all the information was random and not conveyed by a single system of mutual exchange, each component was trying to achieve its goals without worrying about issues and services of common competence between different subjects. The creation of the model was formed by the union between the association of accountants and the University of Turin, and this was possible thanks to the direct involvement and commitment of the of Prof. Flavio Dezzani, Director of the Department of Management and Accounting of the University of Torino. The common purpose was to develop and promote specialized training and continuing education that the Local Accountants Board of Torino on the specialized multidisciplinary point of view, on the other the object of the University was to promote innovative aspects related to professional accounting and culture and scientific analysis of accounting science. In this first phase the agreements are informal, then the first formal agreements will be made. The first cause of the creation of the network was the facilitation of institutional relations in order to increase the development of small and medium-sized enterprises. The subsequent phases have led to the development of the model involving Chambers of Commerce, Representatives of the category, Institutional Bodies in the area, Entities instrumental in supporting the order of accountants, other universities and other State bodies such as the Court and the Ministry of Justice. Furthermore, this phase of the model became necessary due to the lack of communication between institutions that diminished the efficiency and effectiveness of their activities. The expansion steps of the network are due to the need to respond to new challenges given by a series of processes aimed at reducing bribes, tackling the economic crisis 
and supporting the Italian OIC body, always in the protection and in need to support enterprise and their long-term survival. The search for sustainability and the development of the territory has led to the sharing of ethical principles first among the members, and in a second moment, the sharing with other professional orders present in the territory to support the enterprises. The leadership within the model was achieved in part by the informal relationships made by Aldo Milanese with the heads of the institutions that became part of the model. Only in a second moment, the approach of the model has become an integral part of the philosophy of the members of the chartered accountant's association. This step has allowed the association of accountants to be the promoter of the activities and the center of the model even today. In the last years, the Local Accountants Board of Torino has been governing the system both through agreements and partnerships formed through informal agreements; in 2016, six agreements were signed, in 2017 there are seven agreements activated, and during the year 2018, on the date of 15/04/2018, there are other two agreements. The basis of agreements, partnerships, and formal agreements forms the basis of the "Torino Model" and involves both public institutions and, in some cases, private and public bodies in the municipal, regional and national territory. The elements identified in the various agreements reveal a prevalence of common characteristics. The exchange of know-how, the exchange of information and training are almost always characteristic elements. The main repercussions of the agreements are identified in the increase in jobs for the territory and at the same time the greater commitment of members of Local Accountants Board of Torino. Among the other relevant elements the study identifies in order of relevance and presence: the increase of the quality offered in the provision of public services by the member institutions, the research and diffusion of a CRS culture and of sustainability in the territory also towards the enterprises, the increase in the protection of legality with the reduction of tax damages and loss of income for the territory, the promotion of the same model of network outside the network, the increase in research and development in the area also through agreements with the University, the growth of the value of the logo and the name of the institutions and of the associated intangible value. However, the governance of the Network is also carried out through institutional work tables of mixed composition, composed of representatives of institutions and institutions in the area as well as the category. This composition ensures a rapid ability to identify needs and respond to problems without limitations due to the bureaucracy of processes. Currently, seventeen work tables are active with the representation of all the institutional components expressed in Figure 1. Even in the work tables the exchange of know-how and specific skills able to respond immediately to needs ensures greater efficiency and effectiveness in the use of resources used in the network. The common well-being and the development of the territory are identified as general objectives of all the relationships within the network, but the best ability to respond to the need through know-how, exchange of information and training and an increase in the quality of services outweigh and deny the limitations that may normally be present within networks, reaching the specific objectives of each network partner. We find ourselves in front of a network that meets the requirements of process management or seeks to identify solutions to identified problems by providing resources and information converging towards common objectives. The characteristics identified in the agreements are the main objectives. However, management through process management does not exclude the use of the constitution theory by introducing new network components to solve emerging problems identified by professionals. The "Torino Model" can, therefore, be defined as a model managed through a mix of the two management approaches.

\section{Discussion}

The concept of new governance identifies four different aspects of public governance in OECD countries since the 90s. For the first time among the proposed models, we also find that of networks. We can identify procedural governments, corporate governance, market governance, and network governance. Each model is associated with different characteristics table 3 (Considine \& Lewis, 2003).

Table 3. Types of Government

\begin{tabular}{lllll}
\hline & Sources of rationality & Forms of control & Primary virtues & Focus on service delivery \\
\hline Procedural government & Law & Rules & Reliable treatments & Universal \\
Corporate Governance & Management & Plans & Address for objectives & Target groups \\
Market governance & Competitors & Contracts & Address given by the costs & Price \\
Network governance & Culture & Coproduction & Flexibility & Clients \\
\hline
\end{tabular}

The study, conducted by Considine and Lewis, analyses all the elements that can influence the different governance models in Australia, England, Germany and New Zealand; the study identifies three factors useful to 
evaluate the different types of governance (procedural, networks and enterprises), concluding that the bureaucratic or procedural organizations have been replaced by models based on corporate governance or networks in most reformist countries (Considine \& Lewis, 2003). Stakeholder theory says that managers should make decisions to take account of the interests of all the stakeholders in an Entity. Stakeholders include all individuals or groups who can substantially affect the welfare of the Entity: not only the financial claimants but also employees, customers, communities, and governmental officials and under some interpretations, the environment, terrorists, blackmailers, and thieves. The network governance model identifies clients as the focus of service delivery. However, in most public institutions we are confronted with an assumption of clients and stakeholders that does not quite fit into governance systems and is imposed as a definition.

Furthermore, in literature, the difference between the objectives of stakeholders and managers is often highlighted, leading to severe difficulty in responding to general needs as opposed to selfish needs (Freeman, 1994). The answers to the questions of how managers should define better worse, and as managers, in fact, do define it, have important implications for the welfare of a society's inhabitants. To the extent that stakeholder theory argues that Entities should pay attention to all their constituencies, the theory is unassailable. Taken this far stakeholder theory is entirely consistent with value maximization which implies that managers must pay attention to all constituencies that can affect the Entity. However, there is more to the stakeholder story than this. Any theory of action must tell the actors, in this case, managers and boards of directors, how to choose among multiple competing and inconsistent constituent interests. Customers want low prices, high quality, expensive service, etc. Employees want high wages, high-quality working conditions, and fringe benefits including vacations, medical benefits, pensions, and the rest. Suppliers of capital want low risk and high returns. Communities want great charitable contributions, social expenditures by Entities to benefit the community at large, stable employment, increased investment, and so on.

Moreover, so, it goes with every conceivable constituency. Any decision criterion and the objective function is at the core of any decision criterion must specify how to make the trade-offs between these often conflicting and inconsistent demands (Jensen, 2010). Added to this is the need of the population towards local and public authorities to guarantee transparency and accountability to allow democratic choices of governance and at the same time reduce tax evasion events (Amuda, 2013; Barbera, Borgonovi, \& Steccolini, 2014; Biancone, Silvana, \& Valerio, 2017). Consistent with a multiple-stakeholder perspective, evaluation of network effectiveness can be viewed at three levels of analysis: the community, the network itself, and the network's organizational participants. These levels are of three broad categories of network constituents: principals, who monitor and fund the network and its activities; agents, who work in the network both as administrators and service-level professionals; and clients, who receive the services provided by the network (Provan \& Milward, 2001). The interviews have highlighted the relationship between subjects, as already expressed by the theory, the ongoing relationship between the members of the board of the Association of accountants and between members of the commissions with public and private bodies of the network led to the construction of the same the formalization of relationships. The interviews and the observation of the functioning of the network confirmed how professionals thanks to the continuous relationships with public and private bodies over time have led to an increase in network size based on the real needs encountered and that these relationships according to need territorial changes also the structure and components of the network itself. The relationship between the primary stakeholders and effectiveness is explained in table 4 . 
Table 4. Summary of network evaluation relationship

\begin{tabular}{|c|c|c|}
\hline \multirow[t]{6}{*}{ Level of network analysis } & Key stakeholders groups & Effectiveness criteria \\
\hline & Principals and clients & Cost to community \\
\hline & Client advocacy & Building social capital \\
\hline & Funders & Public percepitions that problem is being solved \\
\hline & Politicians & Changes in incidence of the problem \\
\hline & Regulators & Aggregate indicators of the client well being \\
\hline \multirow[t]{8}{*}{ Community } & General Public & \\
\hline & Principals and agents & Network membership growth \\
\hline & Primary funders and regulators & Range of services provided \\
\hline & Network administrative organization & Absence of service duplication \\
\hline & Member organizations & Relationship strength (multiplexity) \\
\hline & & $\begin{array}{l}\text { Creation and maintenace of network administrative } \\
\text { organization }\end{array}$ \\
\hline & & Integration/coordination of services \\
\hline & & Cost of network maintenance \\
\hline \multirow[t]{8}{*}{ Network } & & Member commitment to network goals \\
\hline & Agents and clients & Agency survival \\
\hline & Member agency board and manegement & Enhanced legitimacy \\
\hline & Agency staff & Resource acquisition \\
\hline & Individual clients & Cost of services \\
\hline & & Service access \\
\hline & & Client outcomes \\
\hline & & Minimun conflict for multiprogram agencies across \\
\hline Organization/partecipant & & multiple networks \\
\hline
\end{tabular}

The groupings of the main stakeholders and effectiveness never show through the case studies, and examples of such models are feasible and if the results and the answers to the needs are achieved through the proposed criteria. The case study helps to test the theory and fill the gap related to the stakeholder conflict. There is no example of a service network with repercussions and impact on the community based on a Professional Order or professional association in the case studies analyzed in the literature. The case study allows us to highlight that costs are reduced thanks to the transfer of know-how and work between the institutional subjects and the shareholders, providing services to the community. Accountants institutions and enterprises, being present in a uniform manner throughout the territory allow immediate detection of needs and problems immediately identifying an answer to the problem. The exchange of information and training through the technical and institutional tables ensures important inputs and levers that can change the perception of politics by increasing answers closer to the real need. All public administrations and private companies detect the well-being perceived by the population or satisfaction through questionnaires and surveys. The network, however, given the high number of interests in the field could still find some difficulty in comparing the results, even if it is clear from the case study the fallout on the system with an improvement in the quality of service delivery and an increase in efficiency. The case study highlights all the elements of effectiveness related to the network itself. In particular, the number of technical and institutional tables has grown exponentially since the creation of the network, even formal and informal institutional agreements have grown over time, the coordination of services offered is often explicitly directed to the agreements and relationships and contributes to decreasing costs and duplications of services. The promotion of institutions and business partners, as well as the brand and training and information on staff, increase the value of the intangible and the needs of network members and managers. The increase in intangible value and the integration of services, guaranteed by an active collaboration between members of the network, does not conflict with the interests of the community, indeed in this case coincides as both the community and the managers increase the value of institutions and enterprises of belonging, but without clashing with the need for sustainable services and sustainable development of the territory. The gap and conflict detected in the stakeholder's theory are overcome in the common creation of value, without affecting the basic allocation of resources in the system and in the network, indeed leading to an increase in efficiency linked to their use. In Italy, based on the "Torino Model" case study, it is possible to identify the characteristics related to the governance of the network. The common culture is highlighted by the exchange of know-how, information, and training, with the presence in the network of a valid identification of its identity with the "Torino Model." The 
co-production is evident in several formal agreements with the exchange of know-how within the network; some examples are the co-planning and realization of courses, research, public services, reports, institutional advertising, and databases. Flexibility is guaranteed by the search for immediate answers through technical tables and institutional tables. The informal level and the possibility of comparison within the rules of the tables are the essential elements for good flexibility and problem-solving skills. The "Torino Model" thanks to its institutional branches and agreements with private companies, and above all thanks to the presence of a network of members registered with the Order of Accountants of Torino, allows a higher propensity towards customers by offering an immediate response to the need. The case study highlights the prevalent presence of public institutions with the same accounting system. However, this feature does not significantly affect the management of the model, in particular, the presence of a professional order made up of accountants guarantees capacity and flexibility both in accounting and tax terms in responding to the needs also expressed by private companies with a different accounting system. A network formed for the most part by public institutions usually has common objectives, this particularity is able to ensure a more significant response to private partners, without constraining actions and needs, even responding consistently to the needs.

\section{Results and Conclusions}

The "Torino Model" is one of the first examples of network governance at the national level and represents the characteristics already highlighted in the other OECD nations since the 90s. The Network Model allows to overcome various limits and governance constraints present in the other models, identifying it as the best for the management of territorial development, also to protect the sustainability and quality offered by institutions normally bound by bureaucratic limitations. Therefore, the model is able to respond to all the needs of the stakeholders. The network model is able to respond to the requests and needs of the territory by overcoming the gap in the theory of stakeholders and generating added value for all major stakeholders. The "Torino Model" provides an excellent example of network model and collaborative governance among network components. The study responds to both the gap related to the absence of practical cases to test the functioning of network model and network governance, and also provides evidence of the criteria and elements essential for the operation and dissemination of the model with a growth of the territory with evidence of the outputs system positive. The model, which is strictly linked to relatability and the local context, can be considered a best practice for the possible creation of a virtuous network between institutions, the case provides an interesting analysis that highlights how strong leadership in a professional association can provide the input for the formation of a first embryonic model, the maintenance and sharing with the partners together with the two main characteristics identified could make the model stable. Although the case study is unique and not comparable with other cases treated in the literature, it provides a useful example that can be reproduced in other contexts with the same organizational characteristics. The essential elements linked to know-how, the exchange of training and information and therefore the growth of intangible value constitute the essential basis for the establishment of a successful network; this is also highlighted by the case study. The growth of employment on the territory, the sustainability and the quality of services are important direct and indirect repercussions of a network model. The "Torino Model" case highlights the governance characteristics already highlighted by other reformist countries that have been experiencing economic and social well-being for some years, perhaps thanks to the spread of local networks. The rationalization of resources, the increase and coordination between services offered by the network, the increase in quality and the volume of services offered thanks to the interaction between institutions with the consequent increase in added value are the effectiveness criteria that all components of the network and allow to overcome the limitations identified in the literature related to the use of the governance network. It is still a problem to share composite indicators for the evaluation of the common well-being of the community by network members. Contrary to some studies carried out in Anglo-Saxon contexts, the Italian entrepreneurial fabric shows that the private assisted by the professional and the public is able to respond to the same needs without limiting the work. In particular, small and medium-sized Italian companies, which make up the majority of the Italian economy (Corbetta, 1995; Del Giudice et al., 2017; Russo \& Tencati, 2009) are aware that the survival of the company is linked to the training and growth of its employees. This purpose is achieved through a fair remuneration (Riley, Michael, \& Mahoney, 2017) and this is only possible with active collaboration with professionals (Spence, Sturdy, \& Carter, 2018) and institutions in order to tackle economic evolution and the possible internationalization (Dimitratos, Voudouris, Plakoyiannaki, \& Nakos, 2012). The future perspective will be the analysis of a dashboard of common indicators that allow a uniform detection of all the needs and a greater response to the demand and to the market changes in real time. The network model could be the best approach to lead to future progress in the effectiveness and efficiency of the resources present in the area. Professional orders, and in particular the accountants' orders, due to the presence of specific skills and flexibility linked to the public and private sectors, could be the best promoters of network models in the area, thus responding to the need 
expressed by stakeholders. In order to improve the fallout and support for social growth, it is necessary to increase the network by involving foundations, such as antennas that can better understand the needs and at the same time promote policies of sustainability and development on the territory. Currently, the main "Piero Piccatti and Aldo Milanese" foundation, founded in December 2007, also founded by the Association of Accountants, collaborates in the realization of the most important part for the development of the network and the social fabric, taking care of the training according to the different agreements stipulated by the order.

\section{Acknowledgments}

The work has received a large contribution provided by testimonies of the board of the Order of Accountants of Turin, Pinerolo, Ivrea.

\section{References}

Achrol, R. S. (1996). Changes in the theory of interorganizational relations in marketing: Toward a network paradigm. Journal of the Academy of Marketing Science, 25(1), 56-71.

Agranoff, R., \& McGuire, M. (2001). Big questions in public network management research. Journal of Public Administration Research and Theory, 11(3), 295-326.

Aguilera, R. V, \& Jackson, G. (2003). The cross-national diversity of corporate governance: Dimensions and determinants. Academy of Management Review, 28(3), 447-465.

American Psychological Association. (1972). Ethical standards of psychologists. Washington, DC: American Psychological Association.

Amuda, Y. J. (2013). Empowerment of Nigerian Muslim Households through Waqf, Zakat, Sadaqat and Public Funding. International Journal of Trade, Economics and Finance, 419-424. https://doi.org/10.7763/IJTEF.2013.V4.329

Anderson, C. A., Gentile, D. A., \& Buckley, K. E. (2007). Violent video game effects on children and adolescents: Theory, research and public policy. https://doi.org/10.1093/acprof:oso/9780195309836.001.0001

Barbera, C., Borgonovi, E., \& Steccolini, I. (2014). Bilancio pubblico e Public Governance: l'esperienza milanese del" Bilancio in Arancio". Azienda Pubblica, (2), 148-165.

Bardach, E., \& Lesser, C. (1996). Accountability in human services collaboratives-For what? and to whom? Journal of Public Administration Research and Theory, 6(2), 197-224.

Beach, S., Keast, R., \& Pickernell, D. (2012). Unpacking the connections between network and stakeholder management and their application to road infrastructure networks in Queensland. Public Management Review, 14(5), 609-629.

Beck, C. A. J., \& Sales, B. D. (2001). Family mediation: Facts, myths, and future prospects (pp. 100-102). Washington, DC: American Psychological Association. https://doi.org/10.1037/10401-000

Bell, E., Bryman, A., \& Harley, B. (2018). Business research methods. Oxford university press.

Benington, J., \& Hartley, J. (2001). Pilots, paradigms and paradoxes: Changes in public sector governance and management in the UK. In International Research Symposium on Public Sector Management (pp. 25-37).

Bergman, B., \& Klefsjö, B. (2010). Quality from customer needs to customer satisfaction. Retrieved from http://www.diva-portal.org/smash/record.jsf?pid=diva2:989573

Bernstein, T. M. (1965). The careful writer: A modern guide to English usage (2nd ed.). New York, NY: Atheneum.

Biancone, P. Pietro, Silvana, S., \& Valerio, B. (2017). L'informazione consolidata e gli indicatori Bes: strumenti per una rendicontazione più accessibile ai cittadini. L'esperienza Italiana del Popular Financial Reporting. Rivista Italiana Di Ragioneria E Di Economia Aziendale, 68-85.

Bjork, R. A. (1989). Retrieval inhibition as an adaptive mechanism in human memory. In H. L. Roediger III, \& F. I. M. Craik (Eds.), Varieties of memory \& consciousness (pp. 309-330). Hillsdale, NJ: Erlbaum.

Booher, D. E., \& Innes, J. E. (2002). Network Power in Collaborative Planning. Journal of Planning Education and Research, 21(3), 221-236. https://doi.org/10.1177/0739456X0202100301

Borgonovi, E. (2005). Teoria degli stakeholder e amministrazione pubblica. Azienda Pubblica, 18(2), 201-205.

Borgonovi, E., Marsilio, M., \& Mus, F. (2006). Relazioni pubblico-privato. Condizioni per la competitività. Egea.

Borzel, T. A. (1998). Organizing Babylon-On the Different Conceptions of Policy Networks. Public 
Administration, 76(2), 253-273. https://doi.org/10.1111/1467-9299.00100

Bovaird, T. (2007). Beyond Engagement and Participation: User and Community Coproduction of Public Services. Public Administration Review, 67(5), 846-860. https://doi.org/10.1111/j.1540-6210.2007.00773.x

Brans, M., administration, S. R. P. (1997). The autopoiesis of administrative systems: Niklas Luhmann on public administration and public policy. Retrieved from http://onlinelibrary.wiley.com/doi/10.1111/1467-9299.00068/full

Bruning, S. (1999). Relationships between organizations and publics: Development of a multi-dimensional $\begin{array}{llll}\text { organization-public } & \text { relationship } & \text { scale. } & \text { Retrieved }\end{array}$ https://www.sciencedirect.com/science/article/pii/S036381119980160X

Bryson, J. M. (2004). What to do when stakeholders matter: stakeholder identification and analysis techniques. Public Management Review, 6(1), 21-53.

Bryson, J. M., Crosby, B. C., \& Stone, M. M. (2006). The Design and Implementation of Cross-Sector Collaborations: Propositions from the Literature. Public Administration Review, 66(s1), 44-55. https://doi.org/10.1111/j.1540-6210.2006.00665.x

Campra, M., Oricchio, G., Braja, E., \& Esposito, P. (2014). Sovereign Risk and Public-private Partnership During the Euro Crisis. from https://books.google.com/books?hl=en\&lr=\&id=uGepBQAAQBAJ\&oi=fnd\&pg=PP1\&dq=maura + campra + public + management\&ots $=$ b3fUpGLrAW\&sig=mS01bmUiv1SL3ajI4jnpLxezAUg

Cohen, M. D., March, J. G., \& Olsen, J. P. (1972). A Garbage Can Model of Organizational Choice. Administrative Science Quarterly, 17(1), 1. https://doi.org/10.2307/2392088

Considine, M., \& Lewis, J. M. (2003). Bureaucracy, Network, or Enterprise? Comparing Models of Governance in Australia, Britain, the Netherlands, and New Zealand. Public Administration Review, 63(2), 131-140. https://doi.org/10.1111/1540-6210.00274

Cook, T. D., \& Campbell, D. T. (1979). Quasi-experimentation: Design and analysis for field settings (Vol. 3). Rand McNally Chicago.

Corbetta, G. (1995). Patterns of development of family businesses in Italy. Family Business Review, 8(4), 255-265.

Corbin, J. M., \& Strauss, A. (1990). Grounded theory research: Procedures, canons, and evaluative criteria. Qualitative Sociology, 13(1), 3-21.

Cress, C. M. (2009). Curricular strategies for student success and engaged learning. Retrieved from http://www.vtcampuscompact.org/2009/TCL_post/presenter_powerpoints /Christine\%20Cress\%20-\%20Curricular\%20Strategies.ppt

Cristofoli, D., Macciò, L., \& Pedrazzi, L. (2015). Structure, mechanisms, and managers in successful networks. Public Management Review, 17(4), 489-516.

Cristofoli, D., Meneguzzo, M., \& Riccucci, N. (2017). Collaborative administration: the management of successful networks. Taylor \& Francis.

Dacin, M. T., Oliver, C., \& Roy, J. P. (2007). The legitimacy of strategic alliances: An institutional perspective. Strategic Management Journal, 28(2), 169-187.

De Bruijn, J. A., \& Ringeling, A. B. (1997). Normative notes: Perspectives on networks. WJM Kickert, EH. Klijn \& JFM Koppenjan Managing Complex Networks. Strategies for the Public Sector, Sage Publications, London, 152-165.

Del Giudice, M., Khan, Z., De Silva, M., Scuotto, V., Caputo, F., \& Carayannis, E. (2017). The microlevel actions undertaken by owner-managers in improving the sustainability practices of cultural and creative small and medium enterprises: A United Kingdom--Italy comparison. Journal of Organizational Behavior, 38(9), 1396-1414.

Denzin, N. K., \& Lincoln, Y. S. (1994). Handbook of qualitative research. Sage publications, inc.

Dimitratos, P., Voudouris, I., Plakoyiannaki, E., \& Nakos, G. (2012). International entrepreneurial culture-Toward a comprehensive opportunity-based operationalization of international entrepreneurship. International Business Review, 21(4), 708-721.

Dowding, K. (1995). Model or Metaphor? A Critical Review of the Policy Network Approach. Political Studies, 43(1), 136-158. https://doi.org/10.1111/j.1467-9248.1995.tb01705.x 
Dowdle, C. S., Designs, M. P. A. (2006). Spontaneous accountability. Researchrepository.Ucd.Ie. Retrieved from http://researchrepository.ucd.ie/handle/10197/7021

Driedger, S. D. (1998, April 20). After divorce. Maclean's, 111(16), 38-43.

Driessen, P., \& Glasbergen, P. (1995). Strategies for network management in an agricultural region (pp. 37-51). https://doi.org/10.1007/978-94-011-0766-2_3

Dyer, J. H., \& Singh, H. (1998). The relational view: Cooperative strategy and sources of interorganizational competitive advantage. Academy of Management Review, 23(4), 660-679.

Farnham, D., Hondeghem, A., Horton, S., \& Barlow, J. (2016). New public managers in Europe: Public servants in transition. Springer. $\quad$ Retrieved from https://books.google.it/books?hl=it\&lr=\&id=UJu-DAAAQBAJ\&oi=fnd\&pg=PA3\&dq=Farnham,+D.,+Hon deghem,+A.,+Horton, + S., $+\% 26+$ Barlow, + J.+(Eds.).+(2016).+New+public+managers + in + Europe: + Public + servants + in+transition. + Springer.\&ots $=$ ZC2IdbgBw0\&sig=3myNTiPQaAgKMfQkazHK

Forrer, J., Kee, J. E., Newcomer, K. E., \& Boyer, E. (2010). Public-Private Partnerships and the Public Accountability Question. Public Administration Review, 70(3), 475-484. https://doi.org/10.1111/j.1540-6210.2010.02161.x

Fountain, J. E. (1998). Social capital: Its relationship to innovation in science and technology. Science and Public Policy, 25(2), 103-115.

Freeman, R. E. (1984). Strategic Management: A Stakeholder Approach (Pitman, Boston, MA).

Freeman, R. E. (1994). The politics of stakeholder theory: Some future directions. Business Ethics Quarterly, 409-421.

Friedman, A. L., \& Miles, S. (2002). Developing stakeholder theory. Journal of Management Studies, 39(1), 1-21.

Garvare, R., \& Johansson, P. (2010). Management for sustainability-A stakeholder theory. Total Quality Management \& Business Excellence, 21(7), 737-744. https://doi.org/10.1080/14783363.2010.483095

Gibbs, J. T., \& Huang, L. N. (Eds.). (1991). Children of color: Psychological interventions with minority youth. San Francisco, CA: Jossey-Bass.

Gilbert, D. G., McClernon, J. F., Rabinovich, N. E., Sugai, C., Plath, L. C., Asgaard, G., ... Botros, N. (2004). Effects of quitting smoking on EEG activation and attention last for more than 31 days and are more severe with stress, dependence, DRD2 A 1 allele, and depressive traits. Nicotine and Tobacco Research, 6, 249-267. https://doi.org/10.1 080/1462220041 0001676305

Goleman, D. (2009). What makes a leader? In D. Demers (Ed.), AHSC 230: Interpersonal communication and relationships (pp. 47-56). Montreal, Canada: Concordia University Bookstore. (Reprinted from Harvard Business Review, 76(6), pp. 93-102, 1998).

Graddy, E. A., \& Chen, B. (2006). Influences on the size and scope of networks for social service delivery. Journal of Public Administration Research and Theory, 16(4), 533-552.

Guignon, C. B. (1998). Existentialism. In E. Craig (Ed.), Routledge encyclopedia of philosophy (Vol. 3, pp. 493-502). London, England: Routledge.

Gulati, R. (1995). Social structure and alliance formation patterns: A longitudinal analysis. Administrative Science Quarterly, 619-652.

Gulati, R. (1998). Alliances and networks. Strategic Management Journal, 19(4), 293-317.

Haigh, N., \& Hoffman, A. J. (2012). Hybrid organizations: The next chapter of sustainable business. Organizational Dynamics, 41(2), 126-134.

Halinen, A., \& Törnroos, J.-Å. (2005). Using case methods in the study of contemporary business networks. Journal of Business Research, 58(9), 1285-1297.

Hanf, K., \& Scharpf, F. W. (1978). Interorganizational policy making: limits to coordination and central control (Vol. 1). Sage Publications (CA).

Harrigan, K. R. (1987). Strategic alliances-Their new role in global competition. Columbia Journal of World Business, 22(2), 67-69.

Harrison, J. S., \& Freeman, R. E. (1999). Stakeholders, social responsibility, and performance: Empirical evidence and theoretical perspectives. Academy of Management Journal, 42(5), 479-485. Retrieved from 
http://amj.aom.org/content/42/5/479.short

Healey, D. (2005). Attention deficit/hyperactivity disorder and creativity: An investigation into their relationship (Unpublished doctoral dissertation). University of Canterbury, Christchurch, New Zealand.

Hennart, J. F. (1988). A transaction costs theory of equity joint ventures. Strategic Management Journal, 9(4), 361-374.

Herculano-Houzel, S., Collins, C. E., Wong, P., Kaas, J. H., \& Lent, R. (2008). The basic nonuniformity of the cerebral cortex. Proceedings of the National Academy of Sciences, 105, 12593-12598. https://doi.org/10.1073/pnas.0805417105

Hjern, B., \& Porter, D. O. (1981). Implementation Structures: A New Unit of Administrative Analysis. Organization Studies, 2(3), 211-227. https://doi.org/10.1177/017084068100200301

Hodge, G., \& Greve, C. (2005). Public-Private partnerships: a policy for all seasons? In The Challenge of Public-Private Partnerships: Learning from International Experience (pp. 332-349). Retrieved from https://books.google.com/books?hl=en\&lr=\&id=pKAvNQmpXkUC\&oi=fnd\&pg=PA332\&dq=hodge+and + greve $+2005 \&$ ots $=5 Z$ vxjS1f5m\&sig=9X3vfMRH6Mpe4Wlr2LglhzvoKEw

Hvidman, U., \& Administration, S. A. J. (2013). Impact of performance management in public and private organizations. Retrieved from https://academic.oup.com/jpart/article-abstract/24/1/35/918373

Jacobs, R., \& Goddard, M. (2007). How Do Performance Indicators Add Up? An Examination of Composite Indicators in Public Services. Public Money and Management, 27(2), 103-110. https://doi.org/10.1111/j.1467-9302.2007.00565.x

Jensen, M. C. (2010). Value maximization, stakeholder theory, and the corporate objective function. Journal of Applied Corporate Finance, 22(1), 32-42.

Kickert, W. J. M., Klijn, E. H., \& Koppenjan, J. F. M. (1997). Managing complex networks: Strategies for the public sector.

Klijn, E. H., \& Koppenjan, J. F. M. (2000). Public Management and Policy Networks. Public Management: An International Journal of Research and Theory, 2(2), 135-158. https://doi.org/10.1080/14719030000000007

Klijn, E. H., \& Teisman, G. R. (2003). Institutional and strategic barriers to public - private partnership: An analysis of Dutch cases. Public Money and Management, 23(3), 137-146.

Klijn, E., \& Koppenjan, J. (1995). Managing networks in the public sector: a theoretical study of management strategies in policy networks. Retrieved from http://onlinelibrary.wiley.com/doi/10.1111/j.1467-9299.1995.tb00837.x/full

Klimoski, R., \& Palmer, S. (1993). The ADA and the hiring process in organizations. Consulting Psychology Journal: Practice and Research, 45(2), 10-36. https://doi.org/10.1037/1061-4087.45.2.10

Koliba, C., Meek, J., \& Zia, A. (2010). Governance networks in public administration and public policy. Retrieved from

https://books.google.com/books?hl=en\&lr=\&id=aWDMBQAAQBAJ\&oi=fnd\&pg=PP1\&dq=Koliba+2010 \&ots=5m7AXgRLVo\&sig=T0m7_J5PYvviLuSJeS3CY7Pgk3c

Kubrick, S. (Director). (1980). The Shining [Motion picture]. United States: Warner Brothers.

Laumann, E. O., Galaskiewicz, J., \& Marsden, P. V. (1978). Community structure as interorganizational linkages. Annual Review of Sociology, 4(1), 455-484.

Lecy, J. D., Mergel, I. A., \& Schmitz, H. P. (2014). Networks in public administration: current scholarship in review. Public Management Review, 16(5), 643-665.

Lindblom, C. E. (1965). The intelligence of democracy: Decision making through mutual adjustment. Free Pr.

Liu, S. (2005, May). Defending against business crises with the help of intelligent agent based early warning solutions. Paper presented at the Seventh International Conference on Enterprise Information Systems, Miami, FL. Abstract retrieved from http://www.iceis.org/iceis2005/abstracts_2005.htm

MacIntyre, L. (Reporter). (2002, January 23). Scandal of the Century [Television series episode]. In H. Cashore (Producer), The fifth estate. Toronto, Canada: Canadian Broadcasting Corporation.

McGuire, M. (2006). Collaborative Public Management: Assessing What We Know and How We Know It. Public Administration Review, 66(s1), 33-43. https://doi.org/10.1111/j.1540-6210.2006.00664.x 
McLuhan, M. (1970a). Culture is our business. New York, NY: McGraw-Hill.

McLuhan, M. (1970b). From cliche to archetype. New York, NY: Viking Press.

Meier, K. J., \& O’Toole, L. J. (2003). Public Management and Educational Performance: The Impact of Managerial Networking. Public Administration Review, 63(6), 689-699. https://doi.org/10.1111/1540-6210.00332

Mellers, B. A. (2000). Choice and the relative pleasure of consequences. Psychological Bulletin, 126, 910-924. https://doi.org/10.1037/0033-2909.126.6.910

Mintzberg, H. (2005). Developing theory about the development of theory. Retrieved from http://www.mediastudies.viu.ca/dougstetar/courses/digi301/resources/mintzberg.pdf

Mischen, P. A. (2015). Collaborative network capacity. Public Management Review, 17(3), 380-403.

Nickerson, J. A., \& Silverman, B. S. (1997). Integrating competitive strategy and transaction cost economics: An operationalization of fit in the interstate trucking industry.

O’Toole, L. J. (1988). Strategies for intergovernmental management:implementing programs in interorganizational networks. International Journal of Public Administration, 11(4), 417-441. https://doi.org/10.1080/01900698808524596

O’Toole, L. J. (1997). Implementing Public Innovations in Network Settings. Administration \& Society, 29(2), 115-138. https://doi.org/10.1177/009539979702900201

Osborn, R. N., \& Baughn, C. C. (1990). Forms of interorganizational governance for multinational alliances. Academy of Management Journal, 33(3), 503-519.

Owen-Smith, J., \& Powell, W. W. (2004). Knowledge Networks as Channels and Conduits: The Effects of Spillovers in the Boston Biotechnology Community. Organization Science, 15(1), 5-21. https://doi.org/10.1287/orsc.1030.0054

Oxley, J. E. (1997). Appropriability hazards and governance in strategic alliances: A transaction cost approach. The Journal of Law, Economics, and Organization, 13(2), 387-409.

Pisano, G. P. (1989). Using equity participation to support exchange: Evidence from the biotechnology industry. JL Econ. \& Org., 5, 109.

Pisano, G. P., Russo, M. V, \& Teece, D. J. (1988). Joint ventures and collaborative arrangements in the telecommunications equipment industry. International Collaborative Ventures in US Manufacturing, 23-70.

Pollitt, C., \& Bouckaert, G. (2004). Public management reform: A comparative analysis. USA: Oxford University Press. Retrieved from https://books.google.it/books?hl=it\&lr=\&id=rei8DGQQoooC\&oi=fnd\&pg=PR9\&dq=Pollitt, + C., $+\% 26+$ Bo uckaert, + G. $+(2004) .+$ Public + management + reform: + A+comparative+analysis. + Oxford + University + Press,+ USA.\&ots $=A Q e T x Q 17 y i \& s i g=C-2 j G g U d \ln U L L w y Y W K q n h 5 y t 04 o$

Pollitt, C., \& Bouckaert, G. (2011). Public Management Reform: A Comparative Analysis-New Public Management, Governance, and the Neo-Weberian State. 3. painos. Oxford University Press, USA.

Poocharoen, O., \& Ting, B. (2015). Collaboration, co-production, networks: Convergence of theories. Public Management Review, 17(4), 587-614.

Postman, N. (1979). Teaching as a conserving activity. New York, NY: Delacorte Press.

Postman, N. (1985). Amusing ourselves to death: Public discourse in the age of show business. New York, NY: Viking.

Propper, I. (1996). Success and failure in the management of policy networks. Beleidswetenschap, 10(4), 345-365.

Provan, K. G., \& Milward, H. B. (1995). A preliminary theory of interorganizational network effectiveness: A comparative study of four community mental health systems. Administrative Science Quarterly, 1-33.

Provan, K. G., \& Milward, H. B. (2001). Do networks really work? A framework for evaluating public-sector organizational networks. Public Administration Review, 61(4), 414-423.

Rhodes, R. A. W. (1996). The new governance: governing without government. Political Studies, 44(4), $652-667$.

RHODES, R. A. W., \& MARSH, D. (1992). New directions in the study of policy networks. European Journal of Political Research, 21(1-2), 181-205. https://doi.org/10.1111/j.1475-6765.1992.tb00294.x 
Riley, S. M., Michael, S. C., \& Mahoney, J. T. (2017). Human capital matters: Market valuation of firm investments in training and the role of complementary assets. Strategic Management Journal, 38(9), 1895-1914.

Ring, P. S., \& Ven, A. H. (1989). Formal and informal dimensions of transactions. Research on the Management of Innovation: The Minnesota Studies, 171, 192.

Russo, A., \& Tencati, A. (2009). Formal vs. informal CSR strategies: Evidence from Italian micro, small, medium-sized, and large firms. Journal of Business Ethics, 85(2), 339-353.

Salancik, G. (1995). Wanted: A good network theory of organization. Retrieved from http://www.jstor.org/stable/2393642?casa_token=KDgHRF6nYuMAAAAA:8xFHQ-UirIbqzGug0Odchga Dz80k2qy03yg15zxU_E2hKPc7n8G-M3w6bnpGWS_ZAPFTkznkSbOSaOMEFNQU-jgMsb_14ppldmVL W6Z-hEQ08ThYc9vf

Schilling, M. A. (2000). Decades ahead of her time: advancing stakeholder theory through the ideas of Mary Parker Follett. Journal of Management History (Archive), 6(5), 224-242. https://doi.org/10.1108/13552520010348371

Semenak, S. (1995, December 28). Feeling right at home: Government residence eschews traditional rules. Montreal Gazette, p. A4.

Silverman, D. (2005). Doing qualitative research (2nd ed.). London: Sage.

Sorensen, E., \& Torfing, J. (2005). The Democratic Anchorage of Governance Networks. Scandinavian Political Studies, 28(3), 195-218. https://doi.org/10.1111/j.1467-9477.2005.00129.x

Spence, C., Sturdy, A., \& Carter, C. (2018). Professionals with borders: The relationship between mobility and transnationalism in global firms. Geoforum, 91, 235-244.

Stadtler, L., Journal, G. P.-E. M., \& 2012, undefined. (n.d.). How broker organizations can facilitate publicprivate partnerships for development. Elsevier. Retrieved from https://www.sciencedirect.com/science/article/pii/S0263237311000727

Stewart, J., \& Walsh, K. (1992). Change in the management of public services. Public Administration, 70(4), 499518.

Stoker, G. (1998). Governance as theory: five propositions. International Social Science Journal, 50(155), $17-28$.

Strong, E. K. Jr., \& Uhrbrock, R. S. (1923). Bibliography on job analysis. In L. Outhwaite (Series Ed.), Personnel Research Series: Vol. 1. Job analysis and the curriculum (pp. 140-146). https://doi.org/10.1037/10762-000

Szulanski, G., \& Jensen, R. J. (2006). Presumptive adaptation and the effectiveness of knowledge transfer. Strategic Management Journal, 27(10), 937-957. https://doi.org/10.1002/smj.551

Teece, D. J. (1992). Competition, cooperation, and innovation: Organizational arrangements for regimes of rapid technological progress. Journal of Economic Behavior \& Organization, 18(1), 1-25.

Warner, M. E., \& Hefetz, A. (2008). Managing markets for public service: the role of mixed public--private delivery of city services. Public Administration Review, 68(1), 155-166.

Wettenhall, R. (2007). ActewAGL: a genuine public-private partnership? International Journal of Public Sector Management, 20(5), 392-414. https://doi.org/10.1108/09513550710772512

Wilks, S., Government-industry, M. W. C. (1987). Conclusion: Comparing government-industry relations: States, sectors, and networks. Clarendon Press Oxford.

Wreder, Å., Johansson, P., \& Garvare, R. (2009). Towards a stakeholder methodology: experiences from public eldercare. The TQM Journal, 21(2), 194-202. https://doi.org/10.1108/17542730910938173 


\section{Appendix A}

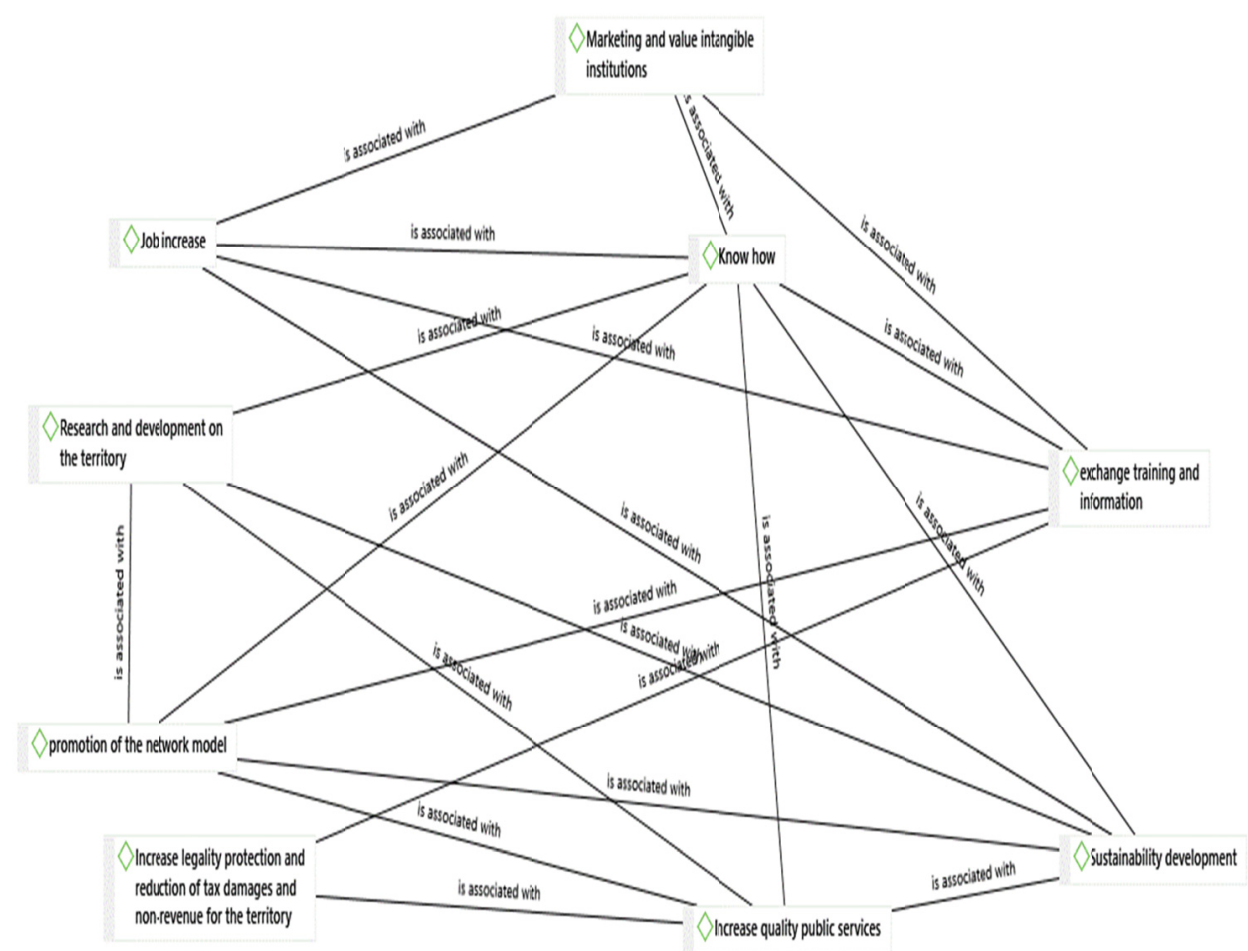

Existing links between characteristic elements present in the formalized minutes. 


\section{Appendix B}

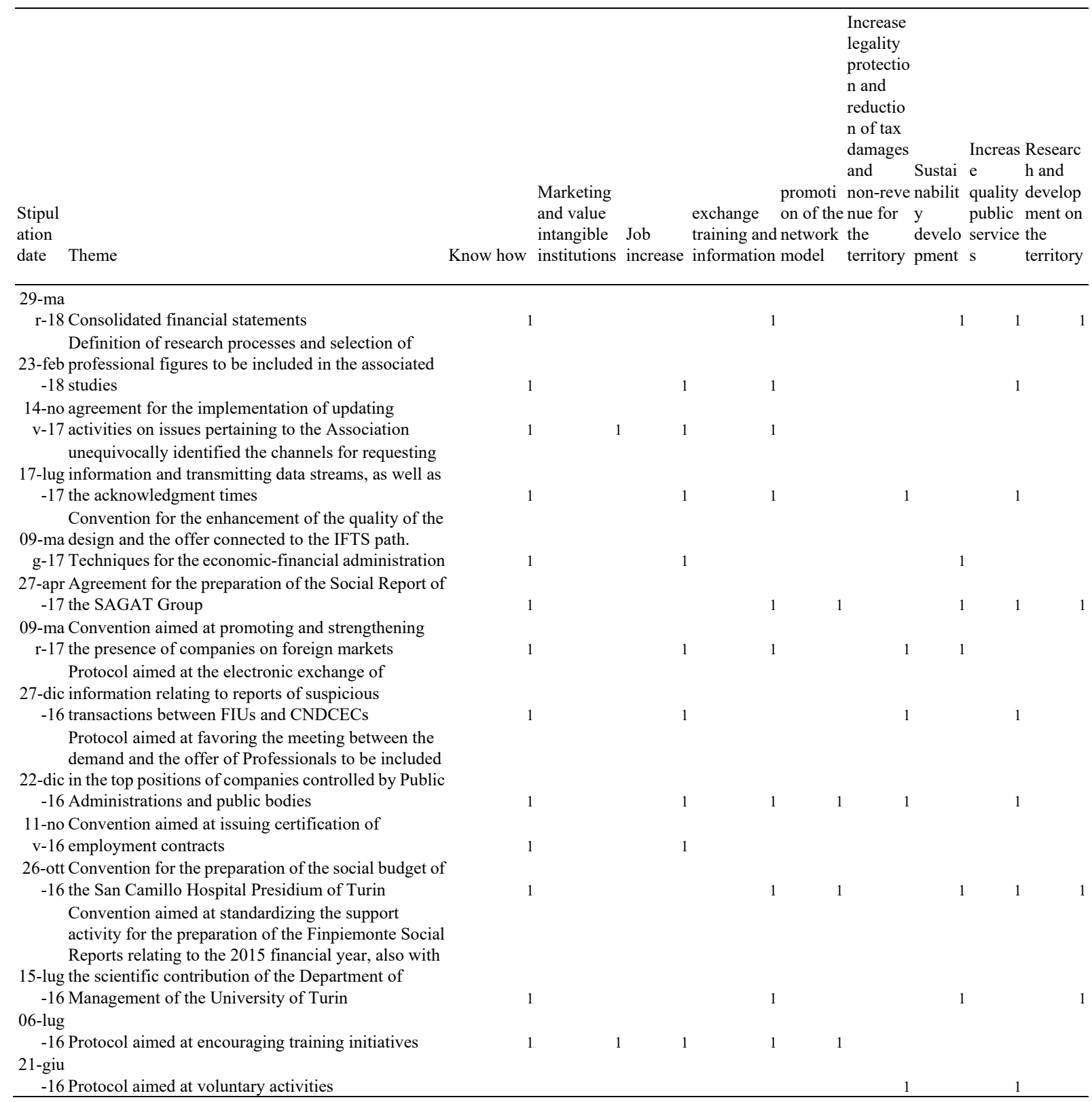

\section{Copyrights}

Copyright for this article is retained by the author(s), with first publication rights granted to the journal.

This is an open-access article distributed under the terms and conditions of the Creative Commons Attribution license (http://creativecommons.org/licenses/by/4.0/). 